\title{
Susceptibility Score Mutations Indicator
}

National Cancer Institute

\section{Source}

National Cancer Institute. Susceptibility Score Mutations Indicator. NCI Thesaurus. Code C156550.

An indication as to whether one or more scored mutations of interest that may confer susceptibility in the microorganism is present. 